\title{
Influence of the maintenance in seismic response of Lorca historic centre masonry residential buildings after the 11 May 2011 earthquake
}

\author{
L. Basset-Salom \& A. Guardiola-Víllora \\ Departamento Mecánica de Medios Continuos y Teoría de Estructuras, \\ Universitat Politècnica de València, Spain
}

\begin{abstract}
Lorca, the city centre of which had been one of the first in Spain to be declared an artistic historic site (1964), is an earthquake prone city. This is the reason why its unreinforced masonry vernacular residential architecture includes reinforcement features (quoins, pegs or ring beams) reducing the seismic vulnerability and improving, consequently, their seismic behaviour. Nevertheless, the seismic response of those buildings to the Lorca May 11th 2011 earthquake was very heterogeneous; it is important to point out that even some of them were demolished in the aftermath of this event. Given that the seismicity and construction and geometric characteristics (load-bearing walls, floors, materials, height, façade layout, etc.) are similar in the historic centre, a comparative study of the vulnerability of a sample of buildings with diverse observed damage degrees has been carried out in order to understand why their seismic response has been different. Results showed that notwithstanding the influence of construction techniques, the level of building maintenance (masonry and roofs) is a determinant factor in lowering the vulnerability of unreinforced masonry structures in historic city centres and in improving their seismic behaviour.

Keywords: Lorca earthquake, maintenance of the Spanish historic centres, masonry residential buildings, seismic response, observed damage.
\end{abstract}




\section{Introduction}

Lorca is an ancient city in southeast of Spain, which seismic activity has been documented from historical sources since 343 BC. (Martinez-Solares and Mezcua-Rodriguez [1]) and from instrumental sources since 1920 (IGN [2]) being the most important earthquakes in 1579, 1674, 1818, 1948, 1977, 1999, 2002 and 2005 (Cabañas et al. [3]).

On May 11th 2011, at 16:47:25, an earthquake of magnitude $M w=5.1$, preceded by a $\mathrm{Mw}=4.5$ foreshock, struck Lorca, followed by a sequence of 135 aftershocks that finished on July $14^{\text {th }}$, caused by the rupture of the "Alhama de Murcia Fault”, spreading underneath Lorca and its environs. The seismic intensities reached by the foreshock and mainshock were very high, VI and VII (Cabañas et al. [3]), respectively, due to the soil amplification, the shallow epicentres location ( 2 and $3 \mathrm{~km}$ ) and the proximity of the city ( 3.5 and $3 \mathrm{~km}$ ).

This earthquake, considered the worst to hit Spain in the last fifty years, resulted in 9 deaths and 324 injured, affecting all the population and producing damage in $80 \%$ of the buildings including historical heritage.

In the aftermath of the earthquake, more than 7800 buildings were inspected (Goula et al. [4]) and preliminarily classified according to the observed damage level by colours: $4.2 \%$ black (collapsed or to be demolished), $8.85 \%$ red (significant structural damage), $17.08 \%$ yellow (low to moderate structural damage, significant to moderate non-structural damage) and $69.87 \%$ green (without structural damage, low to moderate non-structural damage, safe for normal use). Although only one building collapsed during the event, today 1164 buildings have been demolished [5], mainly located in La Viña district, 41\% (reinforced concrete structures), and in the historic centre, 16\% (masonry buildings).

The authors carried out three onsite post-earthquake surveys in order to assess the real seismic vulnerability and damage level of residential buildings. One of these surveys was focused on unreinforced masonry (URM) residential building stock in Lorca's city centre sector II (fig.1), an area included in the Special Protection and Rehabilitation Plan of the Historic and Artistic Site of Lorca (PEPRI [6]). There has been no explicit concern over earthquake protection in in this area so, except for the use of ring beams, quoins or iron ties, hardly any upgrading intervention has taken place to improve their seismic vulnerability.

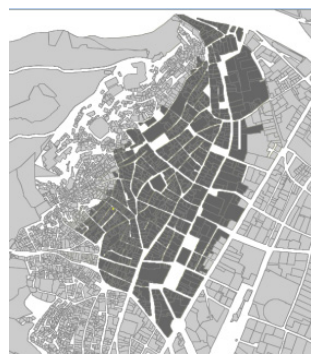

Figure 1: $\quad$ Lorca's city centre sector II. 
Visual information of 1200 buildings regarding geometry, masonry materials, structural and construction characteristics, conservation status, crack patterns and damage level was collected and more than 3000 photographs were taken. Observed data and cadastral records (building age, area, etc.) were stored in a database connected to a Gis system and analysed. During this survey the authors found that, despite of being built at the same period and having, apparently, the same constructive and structural characteristics and dimensions, URM residential buildings in the target area showed very heterogeneous damage (fig. 2).
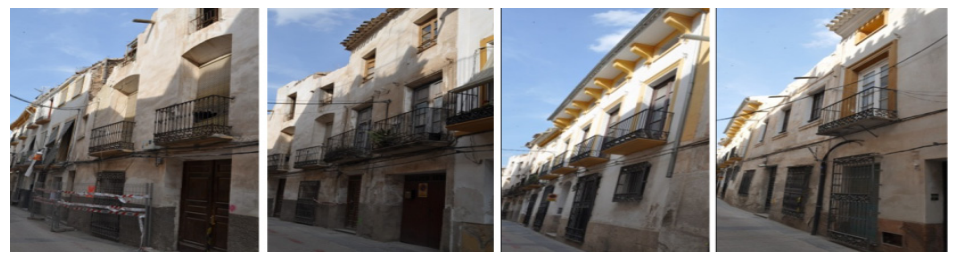

Figure 2: Buildings with heterogeneous damage in Cava Street.

Trying to understand why their seismic response has been so different, a more detailed research has been conducted on a small sample of similar buildings, setting their status before the event using Google Street View (actualized in 2009). For this purpose, a detailed inspection focusing in the definition of all the parameters influencing the seismic behaviour of masonry buildings was carried out, paying special attention to maintenance level, considering that, in this area, a significant number of protected buildings were abandoned before the event.

The seismic vulnerability was then assessed and the failure mechanisms identified with the Failure Mechanisms Identification and Vulnerability Evaluation Method, FaMIVE, (D’Ayala and Speranza [7]) and mapped using the GIS system.

\section{Description of residential masonry buildings in Lorca's historic centre}

Lorca's historic centre is characterized by a very rich heritage (32\% of the buildings have any statutory level of protection) including not only monumental or religious buildings (towers, palaces, churches or monasteries) but also an heterogeneous residential stock, made mainly of unreinforced stone or brick masonry (Catalogue of Protected Buildings [8]).

Masonry fabric varies according to age, style and typology: (a) multi-leaf rubble or poorly cut stone (small or medium sized) with lime mortar; (b) brick masonry with lime, lime-cement or cement mortar; (c) regularly dressed well squared and graded stones blocks (in mansions) and (d) alternating layers of brickwork and rubble (fig. 3).

Along the target area, irregular bulk-shapes blocks are subdivided into plots of different dimensions and street fronts corresponding to: (a) fullrestored and well maintained mansions with residential or administrative use, (b) traditional 


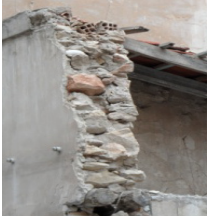

(a)

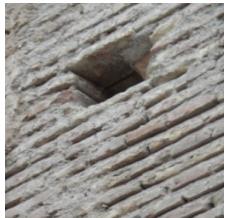

(b)

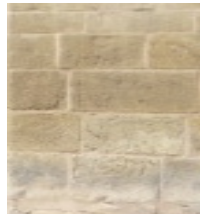

(c)

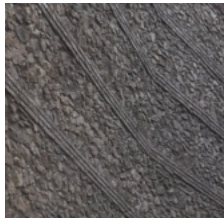

(d)

Figure 3: $\quad$ Masonry fabric: (a) rubble, (b) brick (c) stone blocks, (d) brick and rubble.
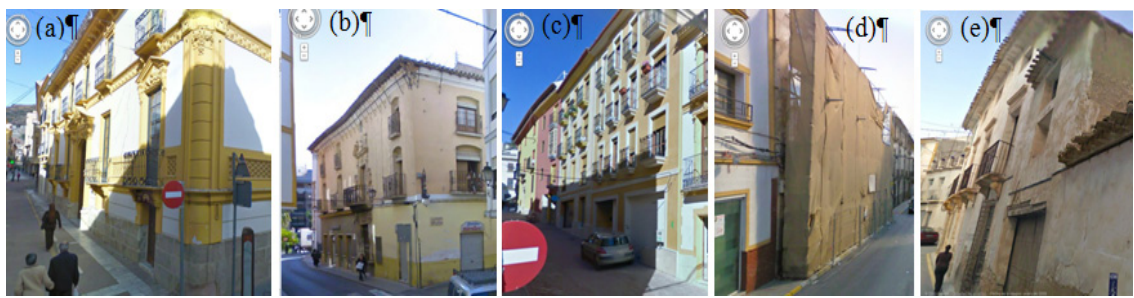

Figure 4: $\quad$ URM buildings before the earthquake (Google street view).

residential buildings with different levels of maintenance, (c) new apartment dwellings replacing the inside of a traditional building but keeping the original masonry façade without structural use, (d) cleaned up buildings with braced façades and (e) abandoned buildings waiting to be declared ruined (fig. 4).

Mostly built in the XVIII and XIX centuries, one to two floor buildings follow a traditional code of practice with bearing walls in simple stone masonry; poorly connected with orthogonal walls or floors; showing deficiencies for the stability under seismic actions. At the end of the XIX century, the quality of stone masonry was improved and the use of bricks for residential dwellings became common, increasing the height up to four storeys (Murphy [9]). Lately, residential masonry buildings were built in brickwork, sometimes with four to six floors.

Horizontal structures (fig. 5) are timber beams for lintels, beams and joists with lightweight masonry vaults in floors (a), timber beams and joists with a traditional horizontal covering made out of reed and plaster (named “cañizo") and tiles in roofs (b) and, recently, reinforced concrete (RC) beams and joists with ceramic vaults (c).
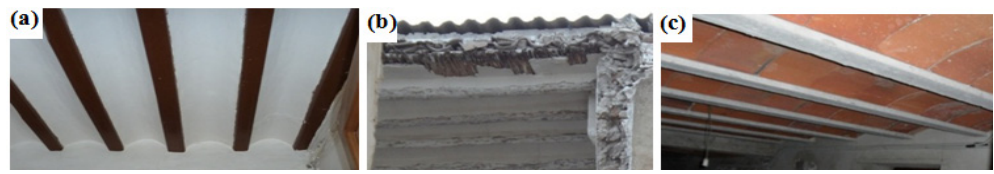

Figure 5: Horizontal structures: (a) timber floors, (b) roofs, (c) RC floors.

The vertical structural system consists of load-bearing masonry orthogonal walls forming the façades and the party walls, carrying floors and roofs (fig 6). 
Sometimes, depending on the building plan, there are interior walls with structural function. It is a common practice that adjacent buildings, when built at the same time, share the party walls, presenting a continuity of the horizontal structure and the roof overhanging. According to the direction of the horizontal structure, the thickness of façades walls ranges from $30 \mathrm{~cm}$ to $80 \mathrm{~cm}$, having, sometimes, significant windows and balconies; whereas the thickness of walls between adjacent buildings ranges from $20 \mathrm{~cm}$ to $30 \mathrm{~cm}$.

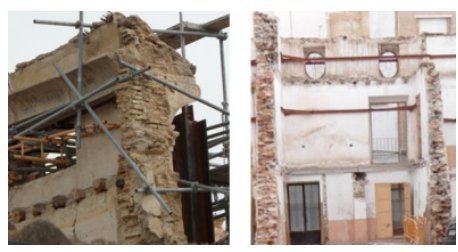

Figure 6: $\quad$ Façades, party walls.

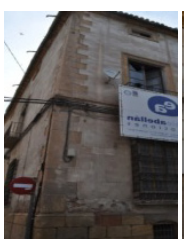

(a)

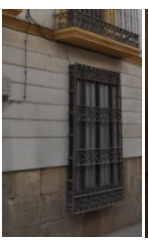

(b)

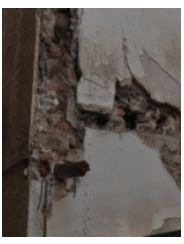

(c)

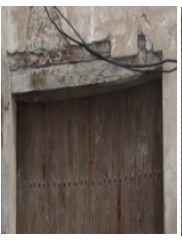

(d)

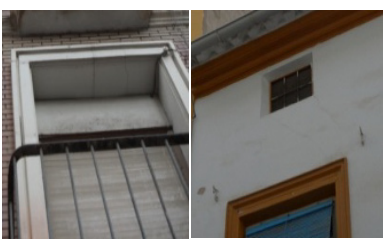

(e) (f)

Figure 7: Reinforcement features (a) quoins, (b) plinths, (c) timber ties or ring beams, (d) timber lintels, (e) stone frames, (f) iron ties.

Being Lorca in a region of moderate seismicity, some reinforcement features (fig. 7) can be found (stone quoins, plinths, floor and wall timber ties or timber ring beams placed horizontally in the middle of the thickness of the wall, timber lintels, stone frames around openings and iron ties)

\section{Damage and seismic vulnerability assessment}

The residential masonry buildings of the sample have been selected and classified in two groups according to the observed damage level, being half of them slightly damaged and the other half moderate to heavily damaged.

Buildings belonging to the first group have been paired with similar ones from the second group attending to masonry typology, constructive and structural characteristics (floor and roof typologies, orthogonal walls, strengthening devices), geometry, position within the block, etc., and, when possible, the age. All the buildings have a statutory protection. The level of maintenance before the event has been set with the Catalogue of protected buildings [8] and Google Street View. Examples of some of the analysed buildings' pairs are described in this paper. 
The first two buildings, no. 48100-23 and no. 47088-1, are shown in fig. 8 and fig. 9. They are located in a corner of the block, which is reinforced with quoins. Façade layout, spandrels and piers dimensions are similar in both cases. Pictures from the Catalogue (1994) and before the earthquake (January 2009) defined their maintenance level (good for building 48100-23 and medium for building 47088-1), confirmed also by the Catalogue's file description. Earthquake effects have been different (see pictures taken in June 2011). While in the first building only a small number of unnoticeable slight cracks appeared, in the second one, the roof failed, the balcony partially collapsed and big cracks occurred in lintels and near the corner.

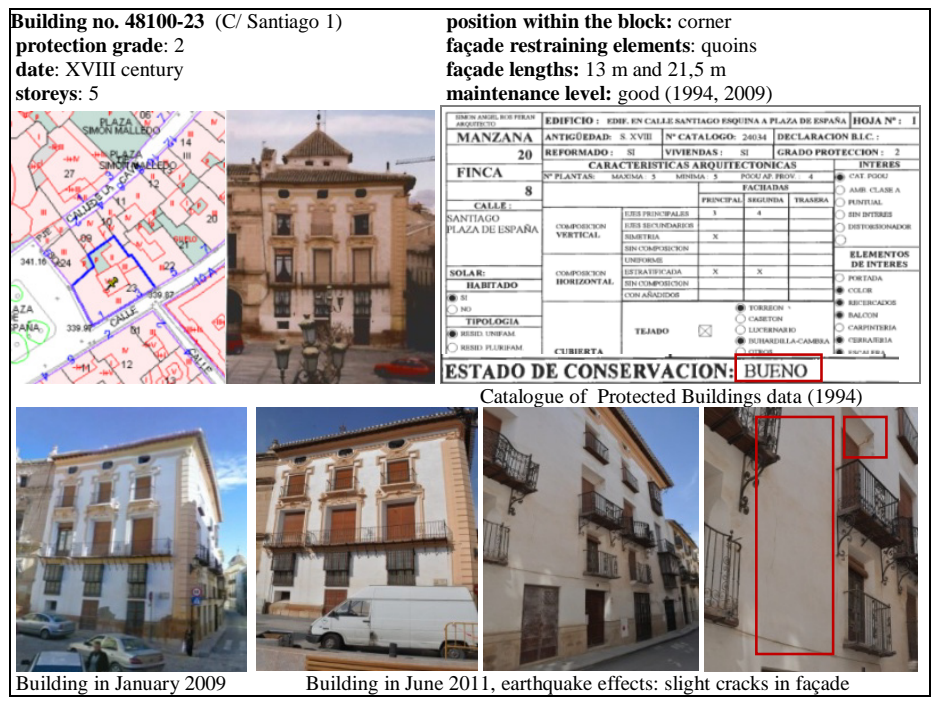

Figure 8: $\quad$ Building no. 48100-23, Santiago Street 1.

The second couple corresponds to adjacent protected houses, in "La Cava" street 48 (no. 49117-20) and 46 (no. 49117-19), built in the XIX century, sharing a partition wall and with nearly identical dimensions, construction techniques and structural characteristics. Masonry fabric consists of rubble stone and floors are made with timber joists orthogonal to the façade strengthened with timber ring beams (fig. 10). According with the Catalogue's file description, the maintenance level in 1994 was good for house no. 48 and medium for no. 46. There isn't any photograph from Google Street View, due to the street dimensions, however, in May 2011, before the earthquake, no. 48 was inhabited and well maintained while no. 46 was abandoned, as was reported by the neighbours. Earthquake effects are shown in fig. 11; while no. 48 has no damage, in no. 46 big cracks in the façade and total failure of the roof can be seen. A summary of both buildings is presented in figs 12 and 13, the only difference being their maintenance level. 


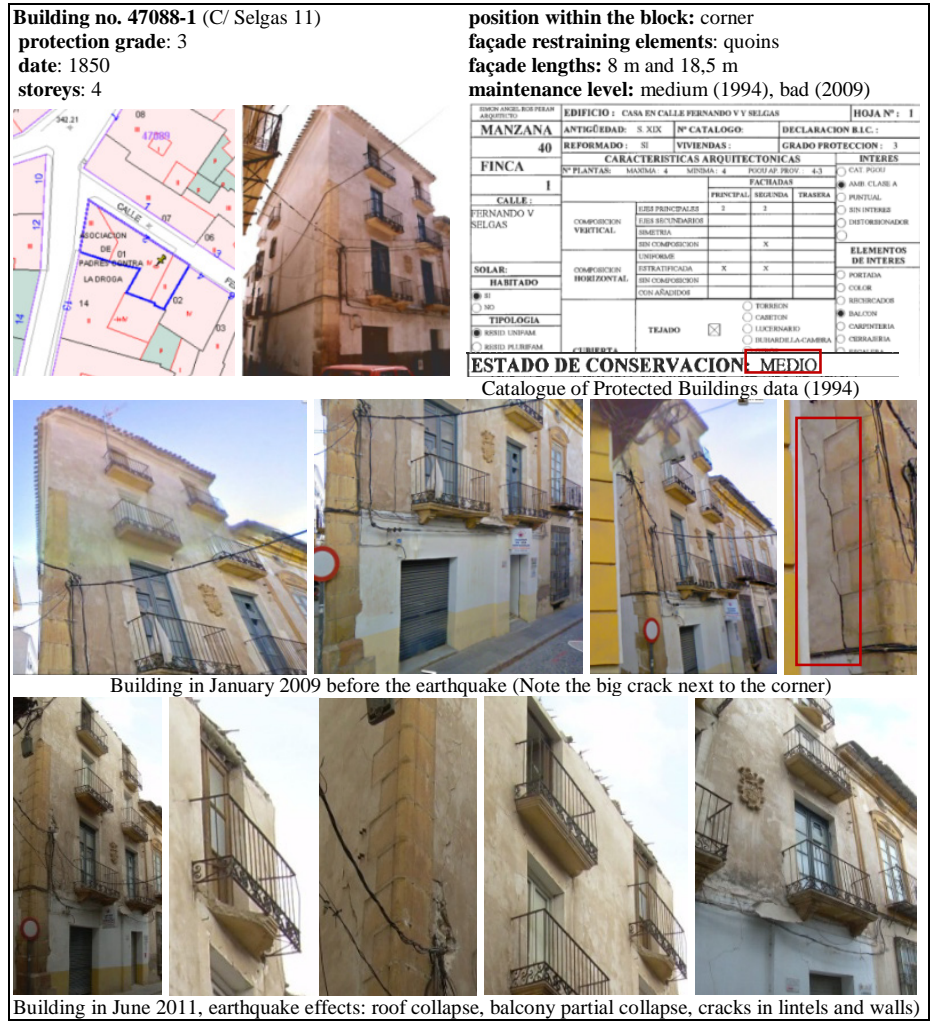

Figure 9: $\quad$ Building no. 47088-1, Selgas Street 11.
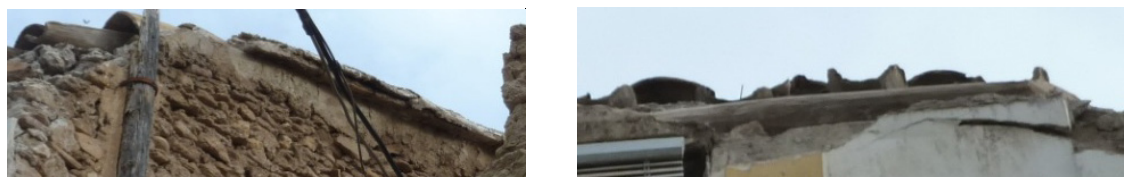

Figure 10: Masonry wall and timber ring beam.
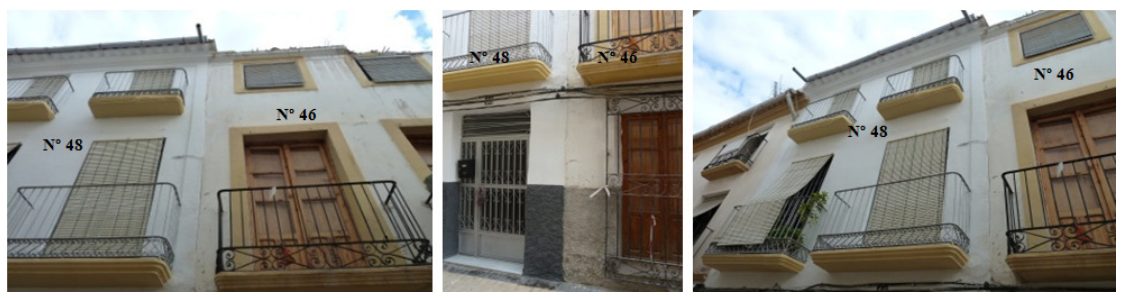

Figure 11: $\quad$ Cava Street 48, 46. 


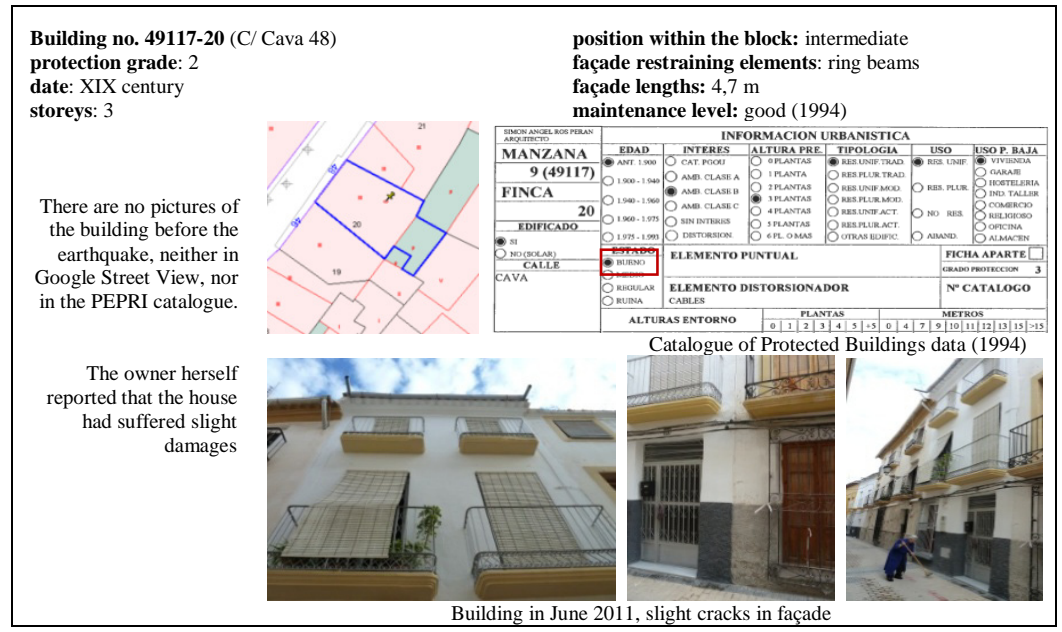

Figure 12: $\quad$ Building no. 49117-20, Cava Street 48.

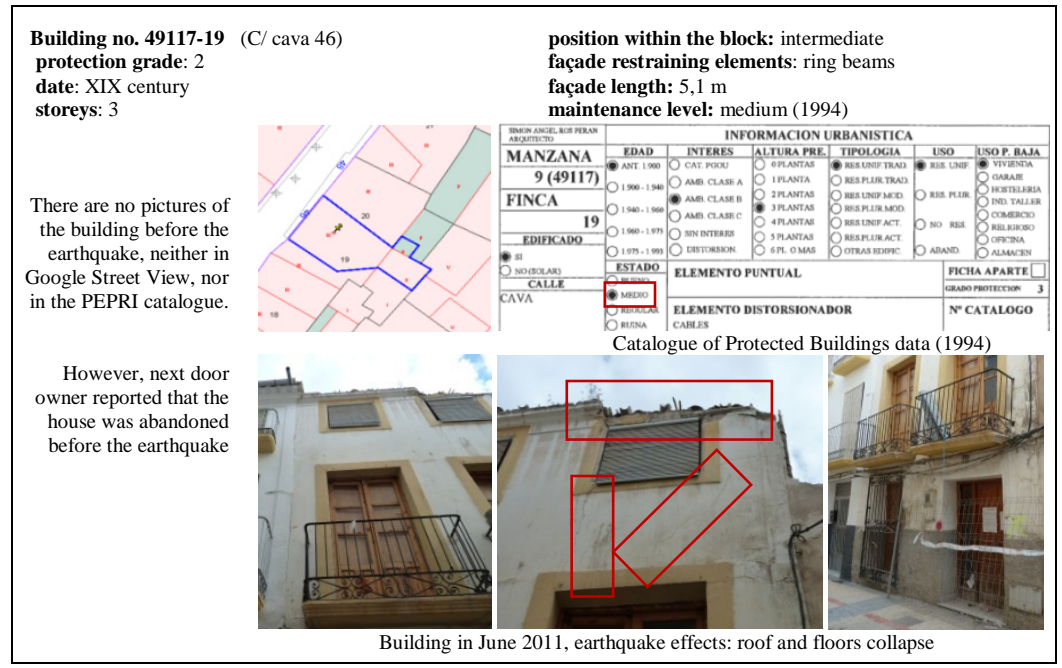

Figure 13: $\quad$ Building no. 49117-19, Cava Street 46.

FaMIVE inspection forms, results and predicted mechanism are shown in fig. 14. The predicted mechanism for both façades is a partial overturning, mechanism D (D’Ayala and Speranza [7]), with a slightly different crack angle (32.22 $2^{\circ}$ for building no. 48 and $35.04^{\circ}$ for no. 46). A total failure of the roof is also predicted, which matches with the observed damage and the crack pattern in house no. 46 (fig. 13) but not with house no. 48. It is worth mentioning that conditions regarding a bad maintenance level are difficult to define accurately, in fact, changing the masonry maintenance level in the FaMIVE inspection form, does not modify the final results of the predicted vulnerability index values, 
damage index, failure mechanism and cracks angle, although this has been the reason for the different seismic performance.

Final results are summarised in fig. 15: $71.43 \%$ of the buildings with a good maintenance level had slight damage, while all the buildings with a medium or bad maintenance level had moderate or heavy damage. However, a good maintenance level was not enough to guarantee a good seismic behaviour, as a small percentage $(7.14 \%)$ of the studied well maintained buildings had heavy damage.

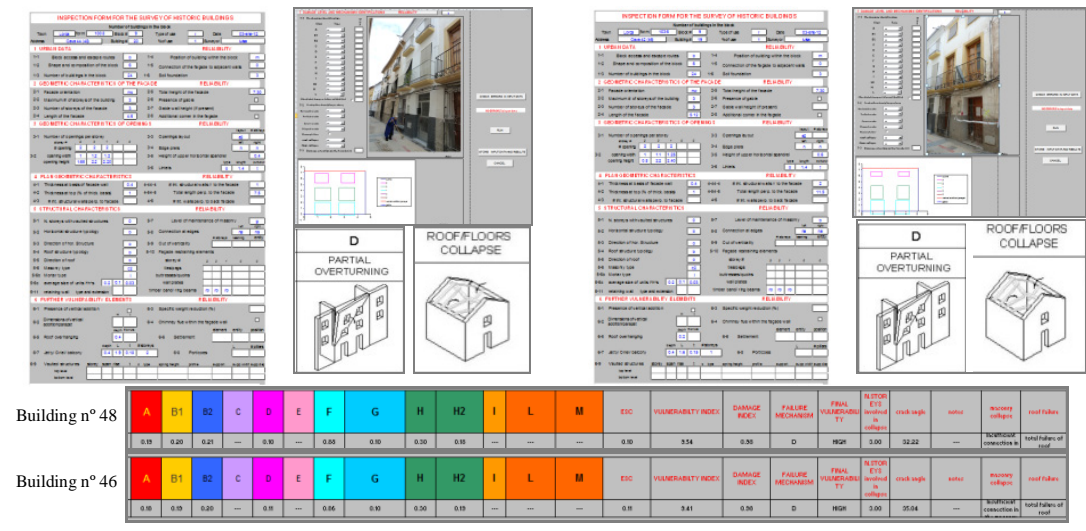

Figure 14: FaMIVE forms and results.

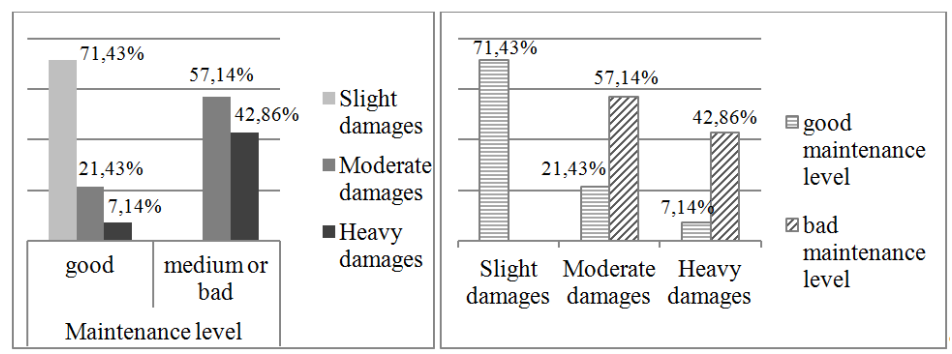

Figure 15: Damage grades and maintenance levels.

One of these buildings is Marin Ponce de Leon Manor House, built by 1630 (fig. 16). Divided into two different vertical properties, it suffered important changes by 1950, when a jetty was built in San Vicente Square's façade, having at this time, a good conservation status, according to the Catalogue's file description and picture, matching with Google Street View (January 2009), except for the jetty which has already been removed. Despite of being well maintained, the effects of the 11 May earthquake were devastating. In the aftermath of the event, firemen had to demolish the overhanging to prevent people to be hurt and a steel structure was built to avoid collapse of the façades. 


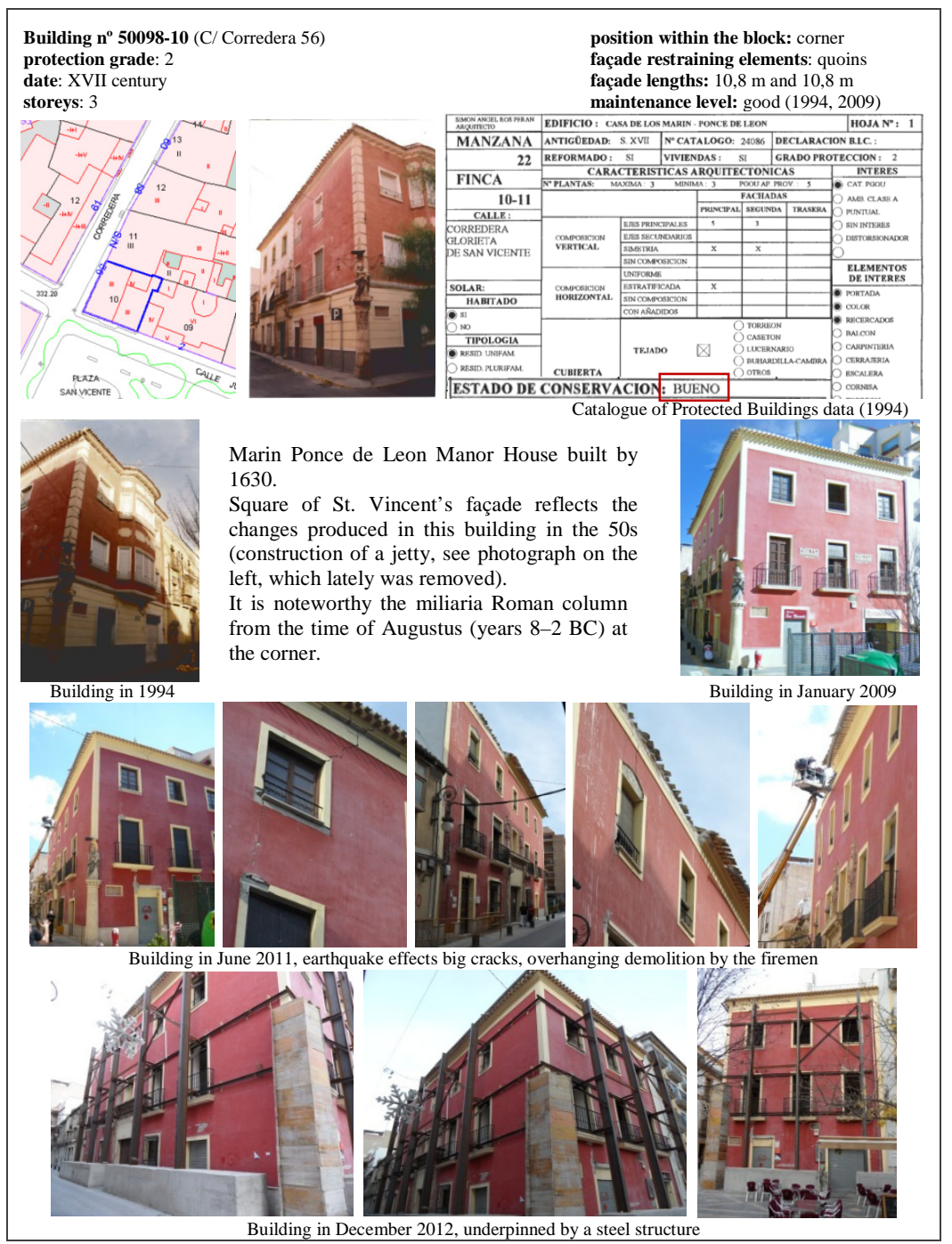

Figure 16: $\quad$ Building $n^{\circ}$ 50098-10, Corredera Street 56.

Due to safety reasons it was not possible for the authors of this study to get into the building in order to define precisely the walls and floor distribution and to search for seismic structural or reinforcing elements. Taking into account that this building has suffered many restructuring processes (according to cadastral database, the house is today divided into four properties: two in the ground floor with commercial use and one with residential use in each floor) and considering new live styles, it can be thought that the original structure and wall distribution has been changed, modifying the seismic behaviour. 


\section{Conclusions}

In this study the authors have compared a sample of unreinforced masonry residential buildings in Lorca's city centre sector II (area included in the Special Protection and Rehabilitation Plan of the Historic and Artistic Site of Lorca) whose response to 11 May 2011 earthquake has been very heterogeneous, although having, apparently, the same geometric, constructive and structural characteristics.

Results of the research reveal that, undoubtedly, the maintenance level has influenced in their seismic behaviour. Well maintained buildings have suffered a widespread but slight and repairable damage (small cracks in the roof overhanging or in the façade and partition walls), being quickly repaired by their owners. However, abandoned or long time unmaintained buildings presented moderate to heavy structural damage (cracks in façades, partial collapse of cornices and balconies, floor and/or roofs partial collapse) with a few number of out of plane mechanisms, giving their owners the opportunity to proceed with demolition, even without maintaining the façades in some cases.

On the other hand, it is important to point out that, in this district, no residential building collapsed during the earthquake, however, in the following months, many demolitions took place, including grade 3 protected buildings, keeping, in those cases, the façades underpinned. The reason to tear down these protected buildings has been not only the damage caused by the earthquake, but also their value in economical terms. Being mostly abandoned, the cost of repairing the damage was considered higher than the value of the building itself (disregarding its heritage value) and, according to the Spanish legislation, a declaration of ruin can be obtained, allowing the heritage building owners to demolish the protected building. Sadly, the opportunity to have a new building within the city centre has not been neglected.

Historical heritage is, unquestionably, an irreplaceable asset that must be preserved. Active cultural and patrimonial policies of intervention including maintenance programs should therefore be stimulated, supported and strengthened to prevent and reduce further decay, degradation and loss, especially in earthquake prone areas where damage can be irretrievable.

\section{References}

[1] Martínez-Solares J.M., Mezcua-Rodriguez J., Catálogo sísmico de la Península Ibérica (880 a. C.-1900). Monografías $n^{\circ}$ 18, Instituto Geográfico Nacional, Madrid, 2002.On line: www.ign.es/ign/.../Catalogohasta1900.pdf.

[2] IGN, Instituto geográfico Nacional. Ministerio de Fomento, 2012 www.fomento.gob.es/mfom/lang_castellano/direcciones_generales/instituto _geografico/geofisica/sismologia/.

[3] Cabañas L., Carreño E., Izquierdo A., Martínez J.M., Capote R., Martínez J., Benito B., Gaspar J., Rivas A., García J., Pérez R., Rodríguez M., Murphy P. Informe del sismo de Lorca del 11 de mayo de 2011. IGN, UCM, UPM, IGME, AEIS. On line: www.ign.es/ign/resources/sismologia/Lorca.pdf. 
[4] Goula X., Irizarry J., Figueras S., Macau A., Barbat A., Carreño L.M., Lantada N., Valcarcel J. El terremoto de Lorca del 11 de Mayo de 2011, Informe de la inspección y de los trabajos de campo realizados, Monografies técniques, Barcelona, IGC, 2011.

[5] Boletin del Ayuntamiento de Lorca, 6/9/2011. www.Lorca.es

[6] PEPRI, Plan Especial de protección y rehabilitación integral del sector II del conjunto histórico artístico de Lorca, Departamento de Urbanismo de Lorca, 2000, www.urbanismo.lorca.es/PEPRI.asp.

[7] D'Ayala D., Speranza E. An integrated procedure for the assessment of seismic vulnerability of historic buildings. Proceedings of 12th European conference of earthquake engineering. Elsevier Science Limited, London, Paper Reference 561, 2002.

[8] Catalogue of Protected Buildings, Departamento de Urbanismo de Lorca, 1994, www.urbanismo.lorca.es/generar/cgi-bin/mapserv.exe.

[9] Murphy P., La Vulnerabilidad de la Edificación de la Región de Murcia (volumen 3), Riesgo Sísmico de la Comunidad Autónoma de la Región de Murcia (RISMUR). Instituto Geográfico Nacional y Dirección General de Protección Civil, 2006. 